\title{
Rheinboldt, o pioneiro
}

\section{PASCHOAL E. SENISE}

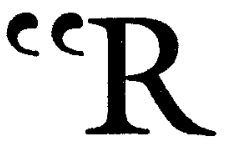

heinboldt além de grande cientista, a um tempo metódico e extremamente criativo, foi também professor extraordinário, possuidor de capacidade didática fora do comum, qualidades essas que não se encontram com freqüência em uma mesma pessoa. As suas aulas fascinavam os alunos pela clareza cristalina de suas explicaçóes acompanhadas por experiências ilustrativas muito bem planejadas, apresentadas e conduzidas com elegância, sem esquecer pormenores que poderiam parecer até insignificantes ou supérfluos, mas que na verdade eram fruto de seu raciocínio lógico resultante, por sua vez, de todo um trabalho prévio imaginativo de profunda reflexão. Além do mais, a sua postura e o seu entusiasmo crescente à medida que ia desenvolvendo a matéria mantinham o interesse dos alunos que acompanhavam a aula sem se dar conta do tempo de sua duração, geralmente prolongada muito além do previsto. Disse alguém que esse brilhante desempenho era fruto de uma vocaçáo professoral inata, que ele sabia explorar com habilidade. Admito que pudesse haver intimamente algo que eu me permitiria chamar de congênito, mas não aceito a explicaçáo de que o aproveitamento desse dom extraordinário era por ele explorado para satisfazer a sua vaidade, ou seja, para conseguir empolgar a platéia de forma exibicionista. Ao contrário, apesar de certa dose de teatralidade, em parte inerente à sua própria personalidade e portanto não intencional, o que realmente o impulsionava era a permanente preocupaçáo com o aluno. Percebi bem essa postura muito consciente quando, após o seu falecimento, em dezembro de 55, na regência interina da cátedra, coube-me, já em março do ano seguinte, ministrar a disciplina de Química Geral e Inorgânica. $O$ curto intervalo de tempo não permitia organizar algo que marcasse, como é mister que aconteça normalmente, o cunho pessoal do docente. Nessa primeira vez, adotei o programa do mestre e procurei, tanto quanto possível, seguir as linhas gerais por ele traçadas para a disciplina, no que fui eficientemente auxiliado pela estimada colega Madeleine Perrier que, sem deixar a pesquisa, já há alguns anos vinha colaborando com o professor nessa tarefa anteriormente desempenhada, sucessivamente, por Herbert Stettiner e Elli Bauer Berthold. Pude então confirmar, pelas anotaçáes deixadas e pelos relatos da colega Madeleine, que a grande preocupaçáo do professor não era a aula em si, mas o aluno. $O$ importante era fazer com que os estudantes pu- 
dessem compreender os conceitos fundamentais e, por isso, procurava colocar-se em nível do aluno, principalmente quando planejava a construçăo de aparelhagem para as experiências demonstrativas, muitas das quais procurava aperfeiçoar ou renovar graças à grande capacidade de imaginaçáo, comparável ao excepcional poder de criatividade que demonstrava no equacionamento e soluçáo dos problemas que enfrentava na pesquisa. Assim é que granjeou notoriedade no âmbito internacional em ambos os campos de atividade.

Mas, Rheinboldt era também historiador da ciência em geral e da química em particular, campo em que foi igualmente considerado autoridade inconteste, autor de obras que deixaram marcas indeléveis na literatura mundial. Adotava com pleno êxito o enfoque histórico em suas aulas e graças à sua vastíssima cultura geral, predominantemente humanística, não apenas conseguia mostrar como a evoluçáo das idéias através dos tempos levava a alterar a interpretaçăo de determinados fenômenos químicos ou físicos, reproduzíveis pelo aluno no laboratório, mas também por que esses mesmos fenômenos tinham sido explicados de maneira diferente à luz de conhecimentos mais limitados em épocas anteriores; ou, então, comprazia-se em mostrar como, às vezes, novas descobertas em outros campos de atividade, a exemplo das áreas econômica, política ou social, poderiam ter proporcionado avanços científicos ou tecnológicos na química.

Rheinboldt gostava de mostrar, sob vários ângulos, a importância do conhecimento histórico como fonte para a compreensáo de caminhos percorridos pela química como ciência básica e aplicada e até mesmo para o ensino. Nesse sentido, é muito pertinente o interessante artigo por ele publicado em 1936, no primeiro número da revista Filosofia, Ciencias e Letras, órgáo do Grêmio da FFCL, sob o título 'As principais fases do desenvolvimento do ensino químico nas universidades'.

\section{(...)}

Em suas aulas, Rheinboldt náo se cansava de mostrar a importância do ensino básico e da pesquisa científica para o progresso da indústria química e criativa e citava exemplos de grandes cientistas que trabalharam na indústria. Costumava dizer que a melhor maneira para se ter uma indústria sólida e florescente é formar bons cientistas.

Rheinboldt, profundo cultor da história, fez dela um instrumento precioso para o desempenho de suas atividades didático-científicas. Em São Paulo, diante das dificuldades enormes que percebeu náo poder vencer em pouco tempo, elaborou um plano de açảo concentrado em poucas disciplinas mas tendo as aulas experimentais como núcleo central 
e dando muita ênfase ao trabalho prático de laboratório em que o aluno era obrigado a executar toda e qualquer tarefa com suas próprias mãos e a usar o seu poder de observação para aprender a raciocinar logicamente em face de suas próprias observaçóes ou de seus resultados. Daí as suas frases muito citadas de aprender pensar quimicamente ou aprender à pensar por fenômenos.

Os resultados dessa orientaçáo foram plenamente satisfatórios, bastando olhar o largo espectro de atividades a que se dedicaram na vida prática os seus antigos alunos, conseguindo muitos deles sobressairem-

Heinrich Rbeinboldt

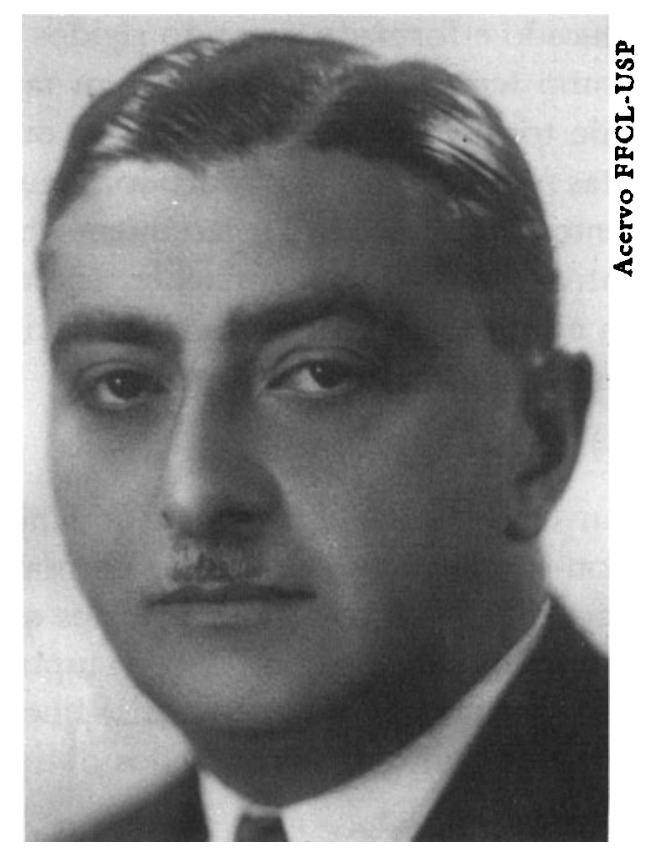

se, tornando-se grandes especialistas em campos os mais variados, até mesmo distantes da química, mas cujo sucesso é por eles mesmos atribuído, em boa parte, ao tipo de treinamento racional que receberam na Escola de Rheinboldt.

Se nos primeiros anos, apesar de todas as dificuldades, Rheinboldt mostrava-se confiante no futuro, até mesmo com certo entusiasmo, com o correr do tempo as suas esperanças foram se esvaindo para dar lugar a uma certa descrença e conseqüente desapontamento. Acostumado em sua universidade, na qual, pela própria posição de destaque que ocupava, a sua voz era respeitada e ouvida, Rheinboldt ficava perplexo em determinados momentos ao ver que suas propostas e opinióes aparentemente 
aceitas, na verdade, muitas vezes, não eram acolhidas, sem que qualquer explicação convincente lhe fosse dada.

Convidado especialmente para construir obra inteiramente nova sentia-se com as mãos atadas pelas limitações de espaço, pela precariedade das instalaçóes, pela rigidez burocrática das normas administrativas que, cerceando-lhe a autoridade e a liberdade de ação, se sobrepunham aos conceitos de ordem acadêmica. Basta lembrar que por volta de 1939 , com a outorga pelo Governo Federal da condição de universidade padrão à Universidade do Brasil, no Rio de Janeiro, o currículo de estudos teve de se amoldar ao da Faculdade Nacional de Filosofia.

Educado e formado segundo rígidos padróes de comportamento e ao mesmo tempo sendo também um tanto tímido, Rheinboldt era incapaz de tomar uma atitude agressiva ou mais enérgica para reivindicar justas providências. Já o professor Hauptmann, que o sucedeu condignamente na direção do Departamento em fins de 1955, adaptou-se com relativa facilidade ao ambiente, entendeu melhor a mentalidade brasileira e conseguia lidar com maior flexibilidade com as autoridades bem como com as pessoas em geral.

\section{(...)}

Convém assinalar que a obra de Rheinboldt, partindo do nada, desenrolou-se num lapso de tempo de pouco mais de vinte anos, que chegam aos vinte e cinco se somarmos os que decorreram na gestão do seu antigo colaborador - professor Hauptmann - à testa do Departamento. Se considerarmos os obstáculos que tiveram de ser enfrentados, poderemos concluir que os resultados obtidos foram plenamente satisfatórios.

A esta altura cabe destacar o acerto dos fundadores da USP ao trazerem do exterior mestres de alto nível que foram capazes de imprimir novas diretrizes ao trabalho acadêmico. Assim, Rheinboldt como Wataghin e vários outros professores estrangeiros, realizaram obra verdadeiramente nacionalista, formando discípulos brasileiros capacitados a dar continuidade ao seu trabalho, ou seja, voltados não apenas à transmissão mas também à geração de conhecimentos.

\section{(...)}

Ao concluir, desejamos acentuar que foi realmente um privilégio para todos os que direta ou indiretamente foram discípulos de Heinrich Rheinboldt, mas, como frisamos reiteradas vezes, não deixamos de reconhecer o papel relevante daqueles que, provindos de outras origens e cujas lideranças acalentavam os mesmos ideais, se juntaram aos primei- 
ros para construir, com muito esforço e dedicação, o Instituto de Química.

Homenageamos pois, todos, a figura ímpar de Rheinboldt não apenas pelo pioneirismo e pelos seus dotes de professor e cientista, mas principalmente porque sintetiza toda uma filosofia de comportamento acadêmico e, portanto, simboliza todos aqueles que contribuíram para o engrandecimento da obra por ele iniciada".

Paschoal E. Senise é professor emérito do Instituto de Química da USP.

Trechos extraídos de Centenutio de Heinrich Rheinboldt 1891-1991 (Instituto de Química da USP, São Paulo, 1993, p. 3-11). 